\title{
Does minimally invasive also stand for minimal patient risk? Lessons from an upper gastrointestinal endoscopy
}

\author{
Luis Manuel Vilardouro Paiva, ${ }^{1}$ Ana Faustino, ${ }^{1}$ Rui Providencia, ${ }^{2}$ \\ Maria Carmo Cachulo ${ }^{2}$
}

'Department of Cardiology, Coimbra's Hospital Centre and University, S.Martinho do Bispo, Coimbra, Portugal ${ }^{2}$ Department of Cardiology, Coimbra's Hospital Center, Coimbra, Portugal

\section{Correspondence to} Dr Luis Manuel Vilardouro Paiva, luisvpaiva@hotmail.com

Accepted 4 March 2014
CrossMark

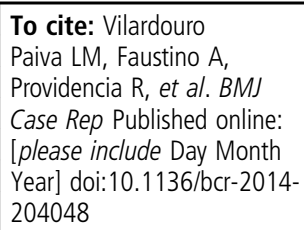

\section{DESCRIPTION}

A 70-year-old man with recent myocardial infarction was referred for upper gastrointestinal endoscopy because of persistent anaemia and iron insufficiency. The procedure was poorly tolerated by the patient, which revealed Barrett"s oesophagus and gastroduodenal angiodysplasia, and since then he started referring hoarseness and dysphagia.

Few weeks later, the patient was readmitted with heart failure and elevated inflammatory parameters, without an identifiable focus of infection. Chest radiograph (figure 1) showed a widened superior mediastinum not previously present, and blood cultures were positive for methicillin-resistant Staphylococcus aureus. He underwent transthoracic echocardiogram that disclosed severe left ventricular dysfunction, no significant valvular disease or vegetations and normal ascending aorta diameter (aortic arch was poorly defined). The patient due to complaints related to the recent endoscopy rejected a transesophageal approach. On the presumption of endocarditis, antibiotic treatment was initiated.

Owing to persistent dysphonia and progressive dysphagia, he underwent indirect laryngoscopy that visualised left vocal cord paralysis in paramedian position. Followed by CT thoracic angiography (figures 2 and 3 ) revealing a saccular structure with calcified foci in the aortic arch $(9 \times 5 \times 4 \mathrm{~cm})$ with compression of the adjacent structures (larynx, oesophagus, recurrent laryngeal nerve). ${ }^{1}$

The patient was deemed unfit for surgery, and was put on long-term antibiotic therapy with possible subsequent aneurysm repair. Few days later, he presented with massive haematemesis resulting from an aortoesophageal fistula, and died of that complication.

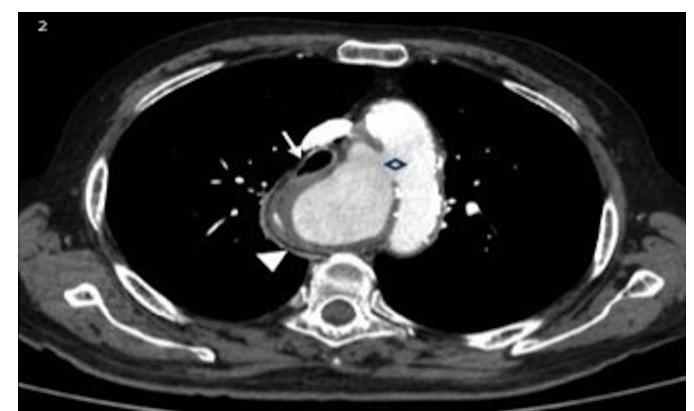

Figure 2 Chest CT angiogram-aortic aneurysm (symbol).

\section{Learning points}

- There are serious risks to be considered even in minimally invasive procedures, which need to be acknowledged by the physician and disclosed to patients.

- Rarely, aortic thoracic aneurysm has been recognised following an upper gastrointestinal endoscopy. The pathophysiological mechanism implies arterial structural changes, predisposing to aortic wall fragility, mostly congenital or age-related.

- Aortic aneurysm rupture risk is ill-defined, however, related to the location and size of the aneurysm. Primary treatment for aortic thoracic aneurysm is surgical repair, and the optimal timing to procedure should be carefully evaluated due to significant surgical mortality risk.

Figure 1 Chest radiograph (posteroanterior and lateral views)—aortic aneurysm (symbol). 


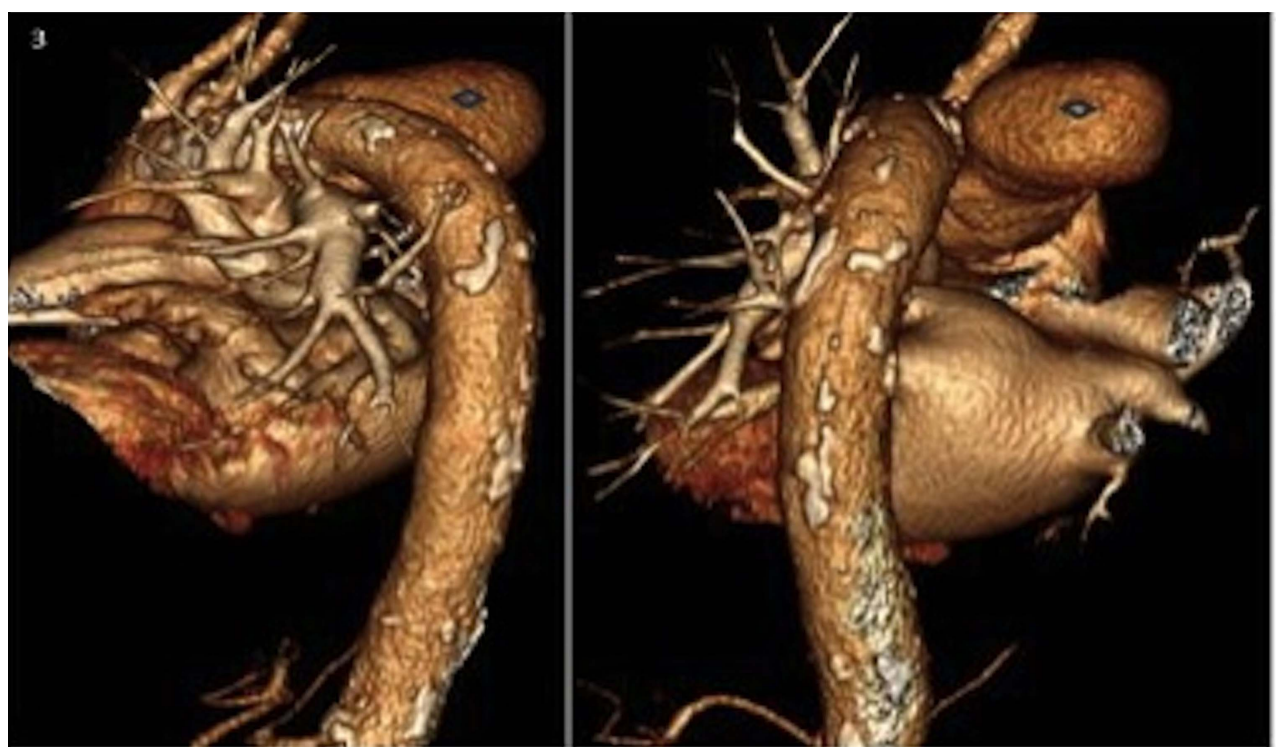

Figure 3 Volume rendering of thoracic aortic aneurysm (symbol).

Contributors All authors had substantial contribution to the conception of this article. Also, they contributed for drafting and revising the manuscript critically for important intellectual content. All authors approved the final version of this work.

\section{Competing interests None.}

Patient consent Obtained.
Provenance and peer review Not commissioned; externally peer reviewed.

\section{REFERENCE}

1 Evangelista A. Diseases of the aorta: aneurysm of the ascending aorta. Heart 2010:96:979-85.

Copyright 2014 BMJ Publishing Group. All rights reserved. For permission to reuse any of this content visit http://group.bmj.com/group/rights-licensing/permissions.

BMJ Case Report Fellows may re-use this article for personal use and teaching without any further permission.

Become a Fellow of BMJ Case Reports today and you can:

- Submit as many cases as you like

- Enjoy fast sympathetic peer review and rapid publication of accepted articles

- Access all the published articles

- Re-use any of the published material for personal use and teaching without further permission

For information on Institutional Fellowships contact consortiasales@bmjgroup.com

Visit casereports.bmj.com for more articles like this and to become a Fellow 